\title{
Effects of ninety minutes per week of continuous aerobic exercise on blood pressure in hypertensive obese humans
}

\author{
Felipe Lovaglio Belozo', Carlos K. Katashima ${ }^{2}$, André V. Cordeiro', Luciene Lenhare, ${ }^{1,2}$, Jean F. Alves ${ }^{3}$, Vagner Ramon Rodrigues Silva ${ }^{1,2, *}$ \\ 'Department of Sport Sciences, School of Applied Science, University of Campinas (UNICAMP), Limeira, Brazil \\ 2Department of Internal Medicine, Faculty of Medical Sciences, University of Campinas (UNICAMP), Campinas, Brazil \\ ${ }^{3}$ Department of Biochemistry, Faculty of Biology, University of Campinas (UNICAMP), Campinas, Brazil
}

The main objective of this study was to examine the effect of continuous aerobic training (CAT) in hypertensive, obese people. Seven patients of average age $(45.3 \pm 3.9$ years), height $(1.63 \pm 0.1 \mathrm{~m})$, body weight $(89.09 \pm 22.0 \mathrm{~kg})$, and body mass index $\left(33.44 \pm 8.6 \mathrm{~kg} / \mathrm{m}^{2}\right)$ were subjected to the training. CAT was performed in thrice-weekly nonconsecutive sessions ( 90 min per week) with intervals of $48 \mathrm{hr}$ between each session. The training sessions entailed 30 min of walking at an intensity of $70 \%-80 \%$ of the maximum heart rate (MHR) on a treadmill over a period of eight weeks, giving a total of 24 sessions. Through correlation analyses, we found significant improvement in the systolic pressure $(R=0.5675, P=0.0253)$ and diastolic pressure $(R=0.7083, P=0.0088)$ when the last session was compared to the first session of training. We found no differences in the diastolic pressure and systolic pressure before, during and after 15 min of the protocol exercise. The program showed a large effect size (ES) for systolic pressure $(E S=0.85)$ and a small ES for diastolic pressure ( $E S=0.33$ ). We found no differences in the blood pressure (BP) and heart rate (HR) during and after the training of obese hypertensive humans, but we found a positively significant correlation between $\mathrm{HR}$ and $\mathrm{BP}$ in the last session and a large ES, suggesting that this protocol exercise might have significance effect in the long term.

Keywords: Blood pressure, Moderate-continuous aerobic training, Hypertension

\section{INTRODUCTION}

Systemic arterial hypertension (SAH) is a chronic disease that affects billions of people around the world. Hypertension causes millions deaths every year (Lim et al., 2012) and is a pivotal factor in the development of cardiovascular disease (CVD), which currently causes the largest number of mortalities per year (Lim et al., 2012). In SAH, the blood pressure (BP) is described as a systolic pressure of $>139 \mathrm{mmHg}$ over a diastolic pressure of $>89 \mathrm{mmHg}$. This causes several pathologies, including coronary artery disease, loss of vision, acute myocardial infarction, stroke, heart failure, and renal failure (Moran et al., 2014). The complications associated with a high BP can stem from various factors, including environmental, nutritional and genetic factors and/or the interaction between these factors and a sedentary lifestyle (Appel, 2017). An elevated heart rate (HR) has been correlated with elevated BP, raising the risk of CVDs (Reule and Drawz, 2012).

A sedentary lifestyle has been described as a public health problem. Since 1995 , in an attempt to improve interest in physical exercise, the World Health Organization has recommended a minimum of 150 min of physical exercise per week (Haskell et al., 2007). Conversely, regular exercise has been considered to act as a "medicine"; it plays a part in the prevention or treatment of several diseases (Stefani and Galanti, 2017) including SAH (Lim et al., 2016; Mancia et al., 2014). Furthermore, it reduces the risk of death from CVDs (Lear et al., 2017).

Out of several physical exercise protocols, aerobic exercise training (AET) is considered to be important for preventing or ameliorating elevated BP (Nascimento et al., 2017; Santos et al., 2016). Evidence suggests that different volumes, frequencies, and inten-
${ }^{*}$ Corresponding author: Vagner Ramon Rodrigues Silva

(iD) https://orcid.org/0000-0003-4793-1075

Department of Sport Sciences, School of Applied Science, University of Campinas (UNICAMP), Limeira, São Paulo, Brazil

Tel \& Fax: +55-19-3521-9038, E-mail: silvavagnerramon@gmail.com

Received: November 17, 2017 / Accepted: January 17, 2018
This is an Open Access article distributed under the terms of the Creative Commons Attribution Non-Commercial License (http://creativecommons.org/licenses/by-nc/4.0/) which permits unrestricted non-commercial use, distribution, and reproduction in any medium, provided the original work is properly cited. 
sities of aerobic training can reverse several CVD pathologies (Brook et al., 2013; Mancia et al., 2014). In light of this, identifying new AET models with which to improve fitness in subjects with CVDs seems to be a good strategy. Thus, the main objective of this study was to investigate whether continuous aerobic training, performed 3 times per week on alternate days (a total of 90 min per week) at an intensity of $70 \%-80 \%$ of the maximal heart rate (MHR) could ameliorate the $\mathrm{HR}$ and $\mathrm{BP}$ in hypertensive obese humans.

\section{MATERIALS AND METHODS}

\section{Subjects}

First, similarly to the study by Damas et al. (2016), this one employed a prior sample size calculation based on a significance of $5 \%(\alpha=0.05)$. The analysis indicated that, at least seven participants were required for the present study given the findings of previous studies concerning the effects of aerobic physical training on obesity (Nassis et al., 2005) and hypertension (Hagberg et al., 2000). Therefore, eight adult subjects were recruited. The volunteers were three males and five females from Unidade do Centro de Saúde II da cidade de Sumaré/SP. Their characteristics follow: hypertension and diabetes (type 2 diabetes mellitus [T2DM]), age ( $45.3 \pm 3$ years), body mass index (BMI) $\left(33.44 \pm 8.6 \mathrm{~kg} / \mathrm{m}^{2}\right)$, height $1.63 \pm 0.1 \mathrm{~m}$, and body weight $89.09 \pm 22.0 \mathrm{~kg}$. The inclusion criteria follow: all the subjects had to be sedentary, obese, hypertensive, diabetic, and nonparticipants in other studies. All subjects were T2DM and were being treated with drugs (metformin, Medley Indústria Farmacêutica Ltda, Campinas, Brazil; Aventis Farmacêutica Ltda, Suzano, Brazil), and (glicemin, Geolab Indústria Farmacêutica, Anapólis, Brazil). Of the seven subjects available, four were using drugs for hypertension (captopril, furosemide, and enalapril, Medley Indústria Farmacêutica Ltda; Aventis Farmacêutica Ltda). The average arterial systolic pressure and average arterial diastolic pressure of the subjects was $140 \mathrm{mmHg} \pm$ $22.08 \mathrm{mmHg}$ and $90 \mathrm{mmHg} \pm 7.21 \mathrm{mmHg}$, respectively. A medical doctor had previously evaluated all the subjects and they had received authorization to practice exercise. Each volunteer was informed of the experimental procedures involving the exercise program and the possible risks associated with the study and subsequently signed the free and informed consent form based on Protocol No. 722/2010 of the Research Ethics Committee of the University of Campinas School of Medical Sciences and following all ethical standards of Resolution 196/96. Afterwards, the subjects were subjected to physical training thrice-weekly every $48 \mathrm{hr}$ over a period of 8 weeks. That translated into a total of 24 sessions. The exclusion criterion for the programs was failure to schedule training or an evaluation. All procedures performed were in accordance with the Declaration of Helsinki.

\section{Physical training program of continuous aerobic exercise}

The physical training program comprised a protocol of continuous aerobic exercise (CAE) on a treadmill (Movement model RT400 PRO). It was divided into thrice-weekly nonconsecutive sessions, with each session lasting $30 \mathrm{~min}$ (90 min per week) and intervals of $48 \mathrm{hr}$ between sessions over a period of 8 weeks. That translated into a total of 24 sessions of moderate-intensity exercise. All sessions were performed in the morning after each participant had consumed his or her usual breakfast at a predetermined time. Each exercise session comprised a 30-min walk at an established intensity of $70 \%$ to $80 \%$ of the MHR. The calculation to find the percentage of the MHR was based on a mathematical prediction protocol adjusted for age (220 - age) (Karvonen et al., 1957). No changes regarding the ingestion of medicine and food were suggested.

\section{Demographic and anthropometric profiles Blood pressure}

BP was taken using a Microlife 3BU1-3 pulse-type from Microlife USA (Dunedin, FL, USA) BP measurement device. It was measured with the subjects in the sitting position for all 24 exercise sessions. These evaluations were performed twice - the first measurement was taken 5 min before the beginning of each exercise session with the subject at rest, and the second measurement was taken $15 \mathrm{~min}$ after each exercise session. After each measurement, the systolic and diastolic BP values were stored in the database for further analysis.

\section{Heart rate}

HR was measured using a cardiac frequency (Polar CS100 model, Polar Electro, New Hyde Park, NY, EUA) for intensity control. The HR was measured before, during and after each exercise session. The first HR measurement was taken at the beginning of each exercise session. After this, the HR was measured every 5 min during the session (at 5, 10, 15, 20, 25, and $30 \mathrm{~min}$ ) and $15 \mathrm{~min}$ after the session ended. This evaluation was performed during all 24 exercise sessions.

\section{Height}

Height was measured using a Wiso wall stadiometer on all sub- 
jects at baseline and in week 8 .

\section{Body mass index}

BMI was calculated using the Quetelet formula (body weight divided by height squared), and this was done in the first and last weeks of the experiment.

\section{Statistical analysis}

The analysis was performed using comparisons between groups were performed using the two-way analysis of variance or Student t-test when necessary or Pearson correlation graphs. All statistics were using Statistic software PrismGraph (Graphpad Software Inc., La Jolla, CA, USA). For all analyses the significance of $P=$ 0.05 was used. Cohen $d$ effect sizes (ESs) were used with $(\leq 0.2)$ representing a small ES, $(0.5)$ a medium ES, and $(\geq 0.8)$ a large ES.

\section{RESULTS}

Table 1 shows all participants, grouping them by similarity in terms of age, sex and anthropometric profile considered obese according to the literature (Romero-Corral et al., 2008). Hypertensive obese humans trained for eight weeks (24 sessions), engaging in continuous treadmill aerobic exercise (90 min per week) and walking at an intensity of $70 \%-80 \%$ of the MHR (see MATERIALS AND METHODS section). Because an elevated HR is associated with elevated BP (Reule and Drawz, 2012), we checked whether the HR improved after the final session. Then we calculated the averages for the first session (1st) and last session (24th) session. No differences were detected between them (Fig. 1A).

Next, using Pearson correlation, we confirmed a positive correlation between HR and systolic pressure or diastolic pressure in the last session of exercise. We observed a significant improvement in systolic pressure $(R=0.5675)$ and diastolic pressure $(R=0.7083)$ values from the previous session (Fig. $1 C, \mathrm{E})$. We did not observe significant differences in the first session (Fig. 1B, D). We examined the systolic $(\mathrm{mmHg}$ ) and diastolic $(\mathrm{mmHg}) \mathrm{BP}$ be-

Table 1. Descriptive characteristics

\begin{tabular}{lc}
\hline Variable & Value \\
\hline Sex & \\
Male & 3 \\
Female & 4 \\
Age $(\mathrm{yr})$ & $45.3 \pm 3.9$ \\
Height $(\mathrm{m})$ & $1.63 \pm 0.1$ \\
Body weight $(\mathrm{kg})$ & $89.09 \pm 22.0$ \\
Body mass index $\left(\mathrm{kg} / \mathrm{m}^{2}\right)$ & $33.44 \pm 8.6$
\end{tabular}

Values are presented as number or mean \pm standard error of the mean.
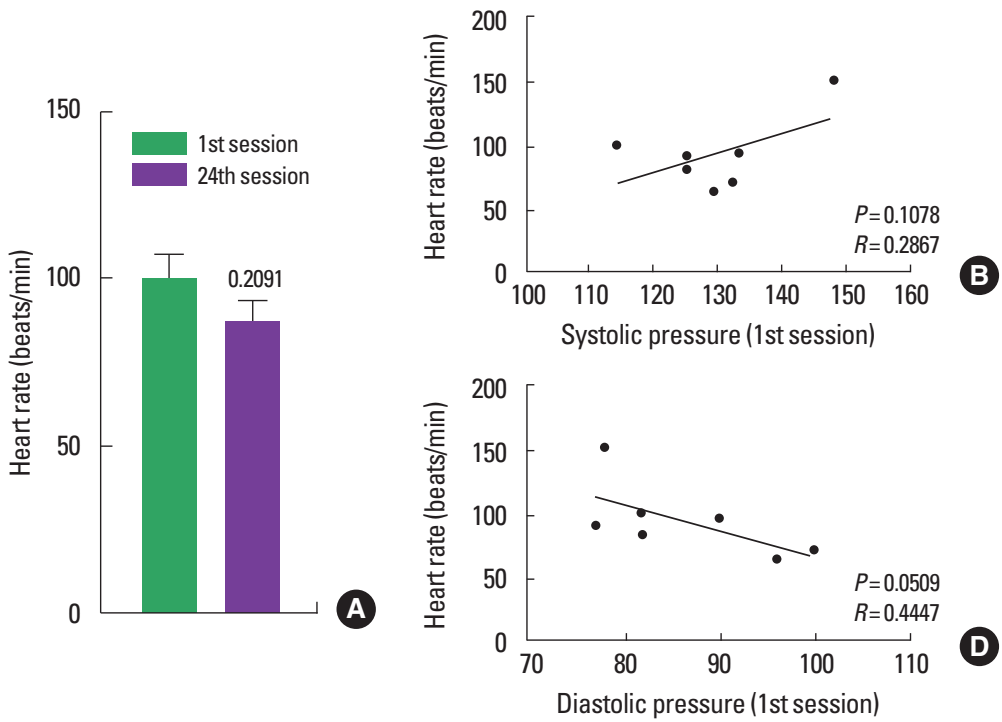
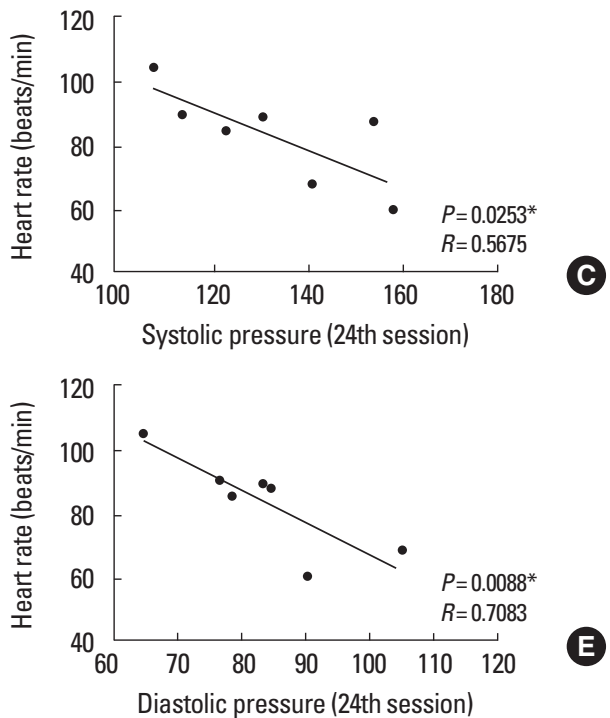

Fig. 1. Heart rate on the 1st and 24th session and correlation between heart rate and blood pressure (systolic/diastolic) of protocol exercise. Average heart rate (A), systolic $(R=0.2867, P=0.1078)$ and diastolic pressure $(R=0.4447, P=0.0509)$ correlated with heart rate up first session $(B$ and $D)$, systolic $(R=0.5675, P=0.0253)$ and diastolic pressure $(R=0.7083, P=0.0088$ ) correlated with heart rate up last session ( $C$ and $E)$. The analysis of heart rate was made between the 1 st and 24 th session of exercise. For Pearson correlation we used the 1st session of heart rate against the 1st session of systolic and diastolic pressure both after 15 min and 24 th session of heart rate against the 24 th session of systolic and diastolic pressure both after $15 \mathrm{~min}$ as well. ${ }^{*} P<0.05$. 
fore and after $15 \mathrm{~min}$ of exercise in all 24 sessions. There was no statistically significant difference (Supplementary Fig. 1A, C). We also analysed the area under the curve for the systolic and diastolic BP before and after $15 \mathrm{~min}$ of exercise in all 24 sessions. We found no differences $(P<0.2949$ for systolic pressure) $(P<0.2621$ for diastolic pressure) (Supplementary Fig. 1B, D). We also evaluated the HR before, during and after each training session (Supplementary Fig. 2A-H).

Finally, to confirm the efficiency of our protocol exercise, we tested the ES according to the literature (Sullivan and Feinn, 2012). We found a large ES for systolic pressure $(E S=0.85)$ and a small $\mathrm{ES}$ for diastolic pressure $(\mathrm{ES}=0.33)$.

\section{DISCUSSION}

CVD affect billions of people all over the world and are risk factors that have been directly correlated with comorbidity and mortality (Lim et al., 2012). Physical inactivity associated with hypertension cases is reported to accompany the risk for mortality (Bouchard et al., 2015). More than 5 million deaths are correlated with physical inactivity (Bouchard et al., 2015). On the other hand, regular exercise can be therapy for the whole body (Stefani and Galanti, 2017). In this context, AET is responsible for changes in cardiac events. The effects of AET are similar to pharmacological treatment and are considered to be responsible for ameliorating or attenuating high BP (Naci and Ioannidis, 2015). Different types of AET have been noted to prevent elevated BP (Cornelissen and Smart, 2013; Pescatello et al., 2004). However, aerobic training requires the control of variables such as the volume, frequency and intensity of training. Here, we use a continuous aerobic training strategy 3 times a week on alternate days to control $\mathrm{BP}$ in hypertensive obese humans.

Studies have suggested that short aerobic training may have positive effects on the BP when it is low in frequency, volume and intensity (Quinn, 2000; Wilmore et al., 2001). Moreover, research has shown that an intensity of up to $30 \mathrm{~min}$ of volume training more than 3 times a week may be helpful in addressing SAH (Brook et al., 2013; Mancia et al., 2014). In our study, we used continuous aerobic training three times a week on alternate days with a 30-min volume of training per session (90 min per week in total) and at an intensity of $70 \%-80 \%$ of the MHR as a strategy for improving the BP in hypertensive obese humans. Studies showed that aerobic exercise at an intensity of $50 \%-75 \%$ of the MHR was enough to ameliorate metabolic parameters such as BP in patients with T2DM (Santos et al., 2016; Zhang et al., 2017).
In our analysis, we did not observe significant differences between the HR and BP values before and after the training of hypertensive obese humans. However, when we analysed the correlation between BP and HR after the last (24th) session, we found it to be of strong statistical significance. Our results confirmed the findings in the literature that indicated that higher HR was associated with higher $\mathrm{BP}$ and could increase the risk of hypertension and CVD. In addition, it is important to highlight that the reduction of the HR, even to a small extent, is considered to be a therapeutic strategy and clinically important in hypertensive people (Reule and Drawz, 2012; Wilmore et al., 2001). Collectively, we established through the ES that our exercise protocol had a strong effect on the systolic pressure. According to the literature, the ES facilitates the understanding of the magnitude of the differences found (Sullivan and Feinn, 2012).

Although we instructed the individuals to continue pursuing their normal dietary habits, we did not control the food they consumed, nor did we measure the daily adverse events that may have occurred during the exercise intervention. Control of the diet is directly related to the maintenance of the $\mathrm{BP}$ and is defined as a major determinant of the development of hypertensiont (Appel, 2017; Lelong et al., 2017); this is especially the case for the consumption of sodium (O'Donnell et al., 2014). We were not able to guarantee that the patients would control their sodium consumption or diets as they were all obese. Lastly, we believe that the intensity and time of the pre- and postexercise evaluations facilitated the achievement of better BP results. Santos et al. (2016) found that exercising at a light intensity and at a moderate intensity (50\% and $75 \%$ of the MHR, respectively) reduced the systolic pressure over $5 \mathrm{hr}$. Zhang et al. (2017) reported that engaging in aerobic exercise at an intensity of $70 \%$ of the maximal HR over a 12-week period was sufficient to reduce the markers of metabolic syndrome in T2DM patients. In our analysis, we evaluated the BP before exercise and 15-min postexercise. Perhaps that was why we did not observe a significant change in BP after the session. In light of this, more research is necessary to investigate the wholebody effects of the present protocol in depth, perhaps analysing the BP at different times after the exercise protocol as well as controlling food and sodium ingestion and the physical activity of individuals.

In line with these observations, we can conclude that our exercise protocol did not improve the BP and HR during and after the training of obese hypertensive humans over an 8-week period. However, we found a positively significant correlation between HR and BP through Pearson's correlation analyses, an important 
parameter in the modulation of hypertension and a large ES in our protocol exercise. It is important to note that regular physical exercise can change several parameters which we did not analyse here and would probably would have significant effects on wholebody metabolism (Stefani and Galanti, 2017). Therefore, we suggest that the protocol involving aerobic physical training at a moderate-to-high intensity ( $70 \%-80 \%$ of the MHR) which the present study proposes may be an alternative strategy for encouraging more people with disorders and pathological conditions to exercise physically once the protocol is easy, fast and enjoyable to perform. In addition, our analyses demonstrate statistically significant correlation between the tendencies to improve the BP, HR, and other beneficial parameters in obese and hypertensive subjects. In this context, it is tempting to speculate that the present protocol, if performed for longer periods (e.g., inducing these individuals to follow a healthy lifestyle, engage in more than 8 weeks of intervention), would play a more statistically significant role in reducing BP in obese, hypertensive people. In addition, a recent study by Thum et al. (2017) demonstrated that physical exercise performed at higher intensities elicited higher enjoyment and adherence by subjects. This validated the protocol employed in the present study (augmenting the intensity and diminishing the volume of training). Our findings indicate that moderate CAE performed in thrice-weekly nonconsecutive sessions ( $90 \mathrm{~min}$ per week) by obese, hypertensive, diabetic and sedentary subjects showed positive correlations between a lower HR and lower BP. Moreover, we found that our protocol training had a large ES.

It's important to highlight that this study has some limitations: first, we did not perform a metabolomics approach to investigating in depth the changes in the whole-body metabolism of the volunteers. In addition, the subjects were instructed to maintain their usual habits and not to improve their control of their food intake and physical activities. Last of all, the small sample size was a possible limitation. However, other studies showed that, where chronic physical exercise (e.g., training) was involved, a sample size of seven or more individuals was sufficient for the rigorous control of the statistical analysis (Damas et al., 2016). Similar studies involving humans used similar sample sizes to detect changes related to physical exercise (Combes et al., 2015; Parker et al., 2017). In general, though this study did not show a statistically significant difference in BP during the training session, our protocol may be an alternative to sedentary life and a determining factor where CVDs are concerned.

\section{CONFLICT OF INTEREST}

No potential conflict of interest relevant to this article was reported.

\section{ACKNOWLEDGMENTS}

We would like to thank the Unit Health Center II of Sumarél São Paulo-Brazil, for collaborating with the study.

\section{SUPPLEMENTARY MATERIALS}

Supplementary Figures 1 and 2 can be found via https://doi. org/10.5213/jer.1835162.581.

\section{REFERENCES}

Appel LJ. The effects of dietary factors on blood pressure. Cardiol Clin 2017;35:197-212.

Bouchard C, Blair SN, Katzmarzyk PT. Less sitting, more physical activity, or higher fitness? Mayo Clin Proc 2015;90:1533-1540.

Brook RD, Appel LJ, Rubenfire M, Ogedegbe G, Bisognano JD, Elliott WJ, Fuchs FD, Hughes JW, Lackland DT, Staffileno BA, Townsend RR, Rajagopalan S; American Heart Association Professional Education Committee of the Council for High Blood Pressure Research, Council on Cardiovascular and Stroke Nursing, Council on Epidemiology and Prevention, and Council on Nutrition, Physical Activity. Beyond medications and diet: alternative approaches to lowering blood pressure: a scientific statement from the american heart association. Hypertension 2013;61:1360-1383

Combes A, Dekerle J, Webborn N, Watt P, Bougault V, Daussin FN. Exercise-induced metabolic fluctuations influence AMPK, p38-MAPK and CaMKII phosphorylation in human skeletal muscle. Physiol Rep 2015; 3. pii: e12462.

Cornelissen VA, Smart NA. Exercise training for blood pressure: a systematic review and meta-analysis. J Am Heart Assoc 2013;2:e004473.

Damas F, Phillips SM, Libardi CA, Vechin FC, Lixandrão ME, Jannig PR, Costa LA, Bacurau AV, Snijders T, Parise G, Tricoli V, Roschel H, Ugrinowitsch $\mathrm{C}$. Resistance training-induced changes in integrated myofibrillar protein synthesis are related to hypertrophy only after attenuation of muscle damage. J Physiol 2016;594:5209-5222.

Hagberg JM, Park JJ, Brown MD. The role of exercise training in the treatment of hypertension: an update. Sports Med 2000;30:193-206.

Haskell WL, Lee IM, Pate RR, Powell KE, Blair SN, Franklin BA, Macera CA, Heath GW, Thompson PD, Bauman A. Physical activity and pub- 
lic health: updated recommendation for adults from the American College of Sports Medicine and the American Heart Association. Med Sci Sports Exerc 2007;39:1423-1434.

Karvonen Mj, Kentala E, Mustala O. The effects of training on heart rate; a longitudinal study. Ann Med Exp Biol Fenn 1957;35:307-315.

Lear SA, Hu W, Rangarajan S, Gasevic D, Leong D, Iqbal R, Casanova A, Swaminathan S, Anjana RM, Kumar R, Rosengren A, Wei L, Yang W, Chuangshi W, Huaxing L, Nair S, Diaz R, Swidon H, Gupta R, Mohammadifard N, Lopez-Jaramillo P, Oguz A, Zatonska K, Seron P, Avezum A, Poirier P, Teo K, Yusuf S. The effect of physical activity on mortality and cardiovascular disease in 130,000 people from 17 highincome, middle-income, and low-income countries: the PURE study. Lancet 2017;390:2643-2654.

Lelong H, Blacher J, Baudry J, Adriouch S, Galan P, Fezeu L, Hercberg S, Kesse-Guyot E. Individual and combined effects of dietary factors on risk of incident hypertension: prospective analysis from the NutriNetSanté Cohort. Hypertension 2017;70:712-720.

Lim SS, Vos T, Flaxman AD, Danaei G, Shibuya K, Adair-Rohani H, Amann M, Anderson HR, Andrews KG, Aryee M, Atkinson C, Bacchus LJ, Bahalim AN, Balakrishnan K, Balmes J, Barker-Collo S, Baxter A, Bell ML, Blore JD, Blyth F, Bonner C, Borges G, Bourne R, Boussinesq M, Brauer M, Brooks P, Bruce NG, Brunekreef B, Bryan-Hancock C, Bucello C, Buchbinder R, Bull F, Burnett RT, Byers TE, Calabria B, Carapetis J, Carnahan E, Chafe Z, Charlson F, Chen H, Chen JS, Cheng AT, Child JC, Cohen A, Colson KE, Cowie BC, Darby S, Darling S, Davis A, Degenhardt L, Dentener F, Des Jarlais DC, Devries K, Dherani M, Ding EL, Dorsey ER, Driscoll T, Edmond K, Ali SE, Engell RE, Erwin PJ, Fahimi S, Falder G, Farzadfar F, Ferrari A, Finucane MM, Flaxman S, Fowkes FG, Freedman G, Freeman MK, Gakidou E, Ghosh S, Giovannucci E, Gmel G, Graham K, Grainger R, Grant B, Gunnell D, Gutierrez HR, Hall W, Hoek HW, Hogan A, Hosgood HD 3rd, Hoy D, Hu H, Hubbell BJ, Hutchings SJ, Ibeanusi SE, Jacklyn GL, Jasrasaria R, Jonas JB, Kan H, Kanis JA, Kas ebaum N, Kawakami N, Khang YH, Khatibzadeh S, Khoo JP, Kok C, Laden F, Lalloo R, Lan Q, Lathlean T, Leasher JL, Leigh J, Li Y, Lin JK, Lipshultz SE, London S, Lozano R, Lu Y, Mak J, Malekzadeh R, Mallinger L, Marcenes W, March L, Marks R, Martin R, McGale P, McGrath J, Mehta S, Mensah GA, Merriman TR, Micha R, Michaud C, Mishra V, Mohd Hanafiah K, Mokdad AA, Morawska L, Mozaffarian D, Murphy T, Naghavi M, Neal B, Nelson PK, Nolla JM, Norman R, Olives C, Omer SB, Orchard J, Osborne R, Ostro B, Page A, Pandey KD, Parry CD, Passmore E, Patra J, Pearce N, Pelizzari PM, Petzold M, Phillips MR, Pope D, Pope CA 3rd, Powles J, Rao M, Razavi H, Rehfuess EA, Rehm JT, Ritz B, Rivara FP, Roberts T, Robinson C, Rodriguez-Portales JA, Romieu I, Room R, Rosenfeld LC, Roy A, Rushton L, Salomon JA, Sampson U,
Sanchez-Riera L, Sanman E, Sapkota A, Seedat S, Shi P, Shield K, Shivakoti R, Singh GM, Sleet DA, Smith E, Smith KR, Stapelberg NJ, Steenland K, Stöckl H, Stovner LJ, Straif K, Straney L, Thurston GD, Tran JH, Van Dingenen R, van Donkelaar A, Veerman JL, Vijayakumar L, Weintraub R, Weissman MM, White RA, Whiteford H, Wiersma ST, Wilkinson JD, Williams HC, Williams W, Wilson N, Woolf AD, Yip P, Zielinski JM, Lopez AD, Murray CJ, Ezzati M, AlMazroa MA, Memish ZA. A comparative risk assessment of burden of disease and injury attributable to 67 risk factors and risk factor clusters in 21 regions, 1990-2010: a systematic analysis for the Global Burden of Disease Study 2010. Lancet 2012;380:2224-2260.

Lim W, Faulkner J, Lambrick D, Stoner L. Reliability of oscillometric central blood pressure responses to submaximal exercise. J Hypertens 2016;34:1084-1090.

Mancia G, Fagard R, Narkiewicz K, Redon J, Zanchetti A, Böhm M, Christiaens T, Cifkova R, De Backer G, Dominiczak A, Galderisi M, Grobbee DE, Jaarsma T, Kirchhof P, Kjeldsen SE, Laurent S, Manolis AJ, Nilsson PM, Ruilope LM, Schmieder RE, Sirnes PA, Sleight P, Viigimaa M, Waeber B, Zannad F; Task Force for the Management of Arterial Hypertension of the European Society of Hypertension and the European Society of Cardiology. 2013 ESH/ESC practice guidelines for the management of arterial hypertension. Blood Press 2014; 23:3-16.

Moran AE, Roth GA, Narula J, Mensah GA. 1990-2010 global cardiovascular disease atlas. Glob Heart 2014;9:3-16.

Naci H, Ioannidis JP. Comparative effectiveness of exercise and drug interventions on mortality outcomes: metaepidemiological study. Br J Sports Med 2015;49:1414-1422.

Nascimento LS, Santos AC, Lucena J, Silva L, Almeida A, Brasileiro-Santos MS. Acute and chronic effects of aerobic exercise on blood pressure in resistant hypertension: study protocol for a randomized controlled trial. Trials 2017;18:250.

Nassis GP, Papantakou K, Skenderi K, Triandafillopoulou M, Kavouras SA, Yannakoulia M, Chrousos GP, Sidossis LS. Aerobic exercise training improves insulin sensitivity without changes in body weight, body fat, adiponectin, and inflammatory markers in overweight and obese girls. Metabolism 2005;54:1472-1479.

O'Donnell M, Mente A, Yusuf S. Evidence relating sodium intake to blood pressure and CVD. Curr Cardiol Rep 2014;16:529.

Parker L, Trewin A, Levinger I, Shaw CS, Stepto NK. The effect of exercise-intensity on skeletal muscle stress kinase and insulin protein signaling. PLoS One 2017;12:e0171613.

Pescatello LS, Franklin BA, Fagard R, Farquhar WB, Kelley GA, Ray CA; American College of Sports Medicine. American College of Sports Medicine position stand. Exercise and hypertension. Med Sci Sports 
Exerc 2004;36:533-553.

Quinn TJ. Twenty-four hour, ambulatory blood pressure responses following acute exercise: impact of exercise intensity. J Hum Hypertens 2000;14:547-553.

Reule S, Drawz PE. Heart rate and blood pressure: any possible implications for management of hypertension? Curr Hypertens Rep 2012;14: 478-484.

Romero-Corral A, Somers VK, Sierra-Johnson J, Thomas RJ, CollazoClavell ML, Korinek J, Allison TG, Batsis JA, Sert-Kuniyoshi FH, Lopez-Jimenez F. Accuracy of body mass index in diagnosing obesity in the adult general population. Int J Obes (Lond) 2008;32:959-966.

Santos LP, Moraes RS, Vieira PJ, Ash GI, Waclawovsky G, Pescatello LS, Umpierre D. Effects of aerobic exercise intensity on ambulatory blood pressure and vascular responses in resistant hypertension: a crossover trial. J Hypertens 2016;34:1317-1324.

Stefani L, Galanti G. Physical exercise prescription in metabolic chronic disease. Adv Exp Med Biol 2017;1005:123-141.

Sullivan GM, Feinn R. Using effect size-or why the P value is not enough. J Grad Med Educ 2012;4:279-282.

Wilmore JH, Stanforth PR, Gagnon J, Rice T, Mandel S, Leon AS, Rao DC, Skinner JS, Bouchard C. Heart rate and blood pressure changes with endurance training: the HERITAGE Family Study. Med Sci Sports Exerc 2001;33:107-116.

Zhang LY, Liu T, Teng YQ, Yao XY, Zhao TT, Lin LY, Jin QS, Jin YJ. Effect of a 12-week aerobic exercise training on serum fetuin-A and adipocytokine levels in type 2 diabetes. Exp Clin Endocrinol Diabetes $2017 \mathrm{Jul}$ 27 [Epub]. https://doi.org/10.1055/s-0043-115904. 


\section{SUPPLEMENTARY MATERIALS}
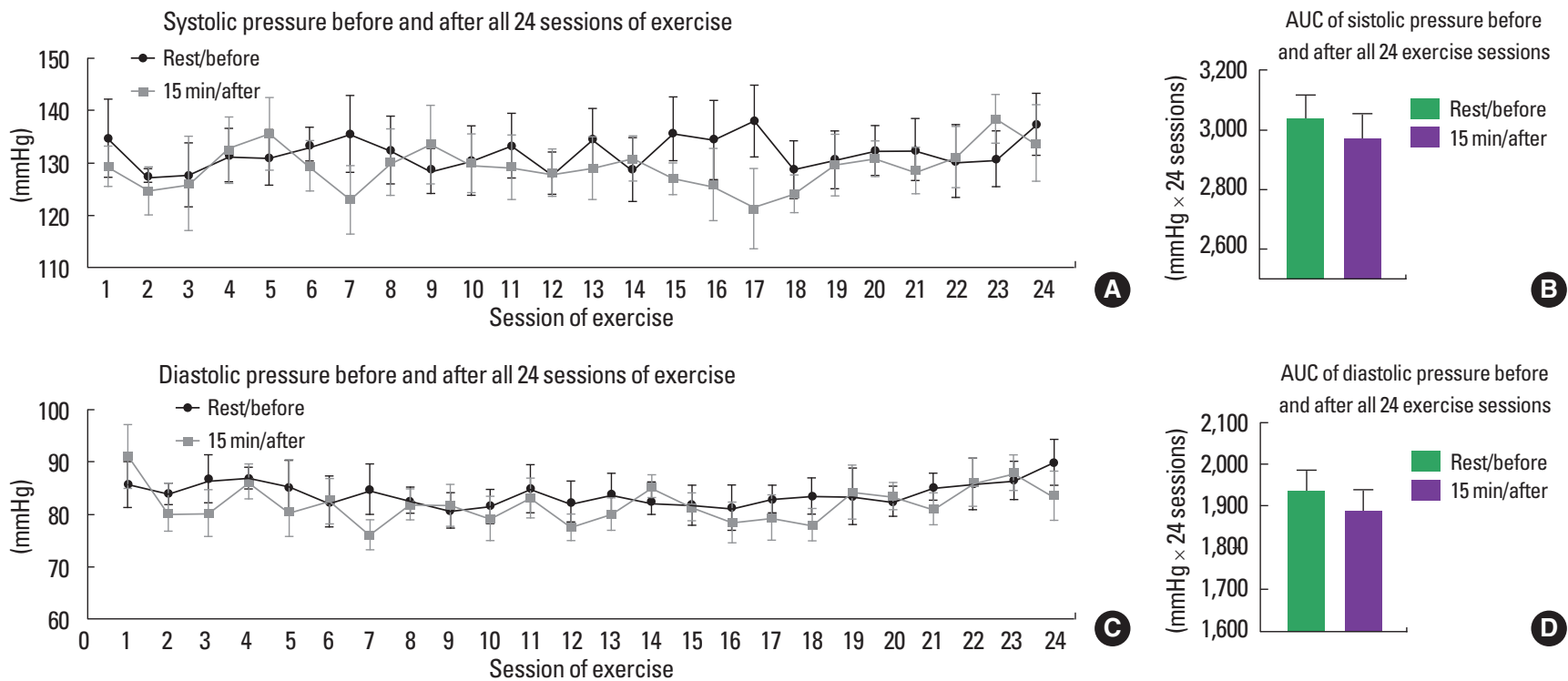

Supplementary Fig. 1. Systolic and diastolic blood pressure before and after all training sessions. (A) Systolic blood pressure before and 15 min after each exercise session $(\mathrm{mmHg})$. (B) Areas under the curve of the systolic blood pressure before and $15 \mathrm{~min}$ after each exercise session (mmHg $\times 24$ sessions). (C) Diastolic blood pressure before and $15 \mathrm{~min}$ after each exercise session (mmHg). (D) Areas under the curve of the diastolic blood pressure before and 15 min after each exercise session ( $\mathrm{mmHg} \times 24$ sessions). AUC, area under the curve. 

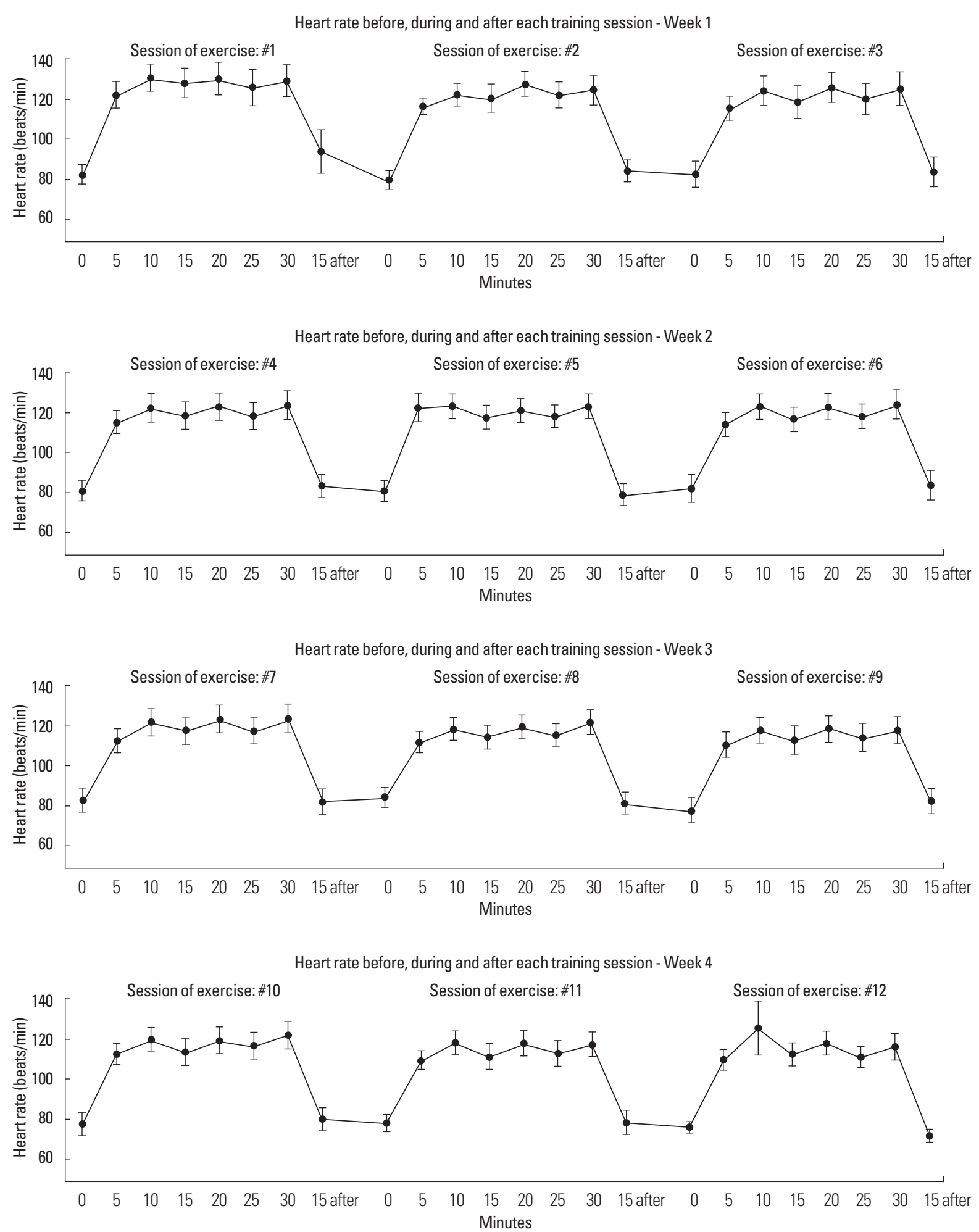

Supplementary Fig. 2. Heart rate per minute before, during and after each of the 24 exercise sessions over 8 weeks (A-H).

(Continued to the next page) 

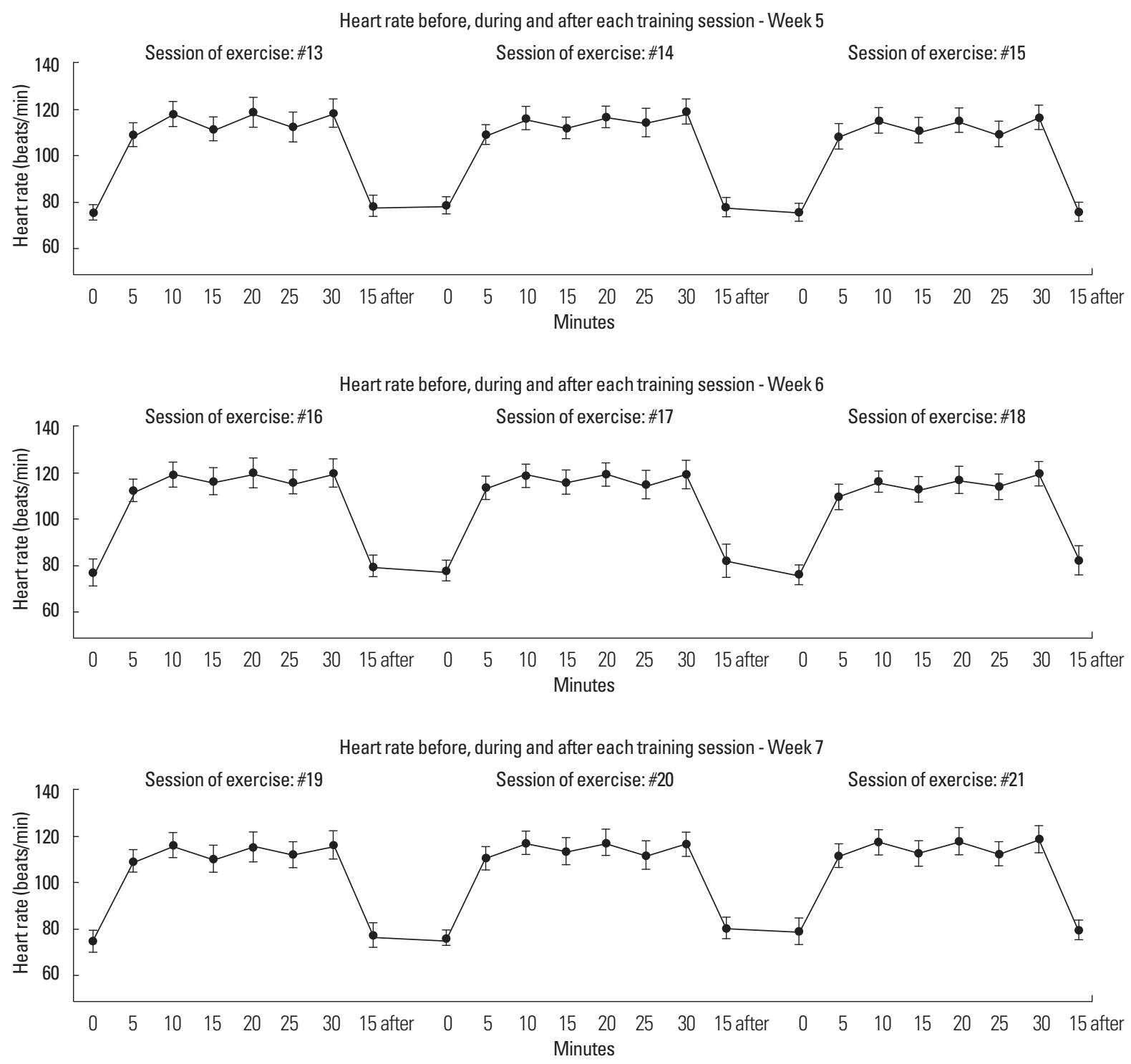

G

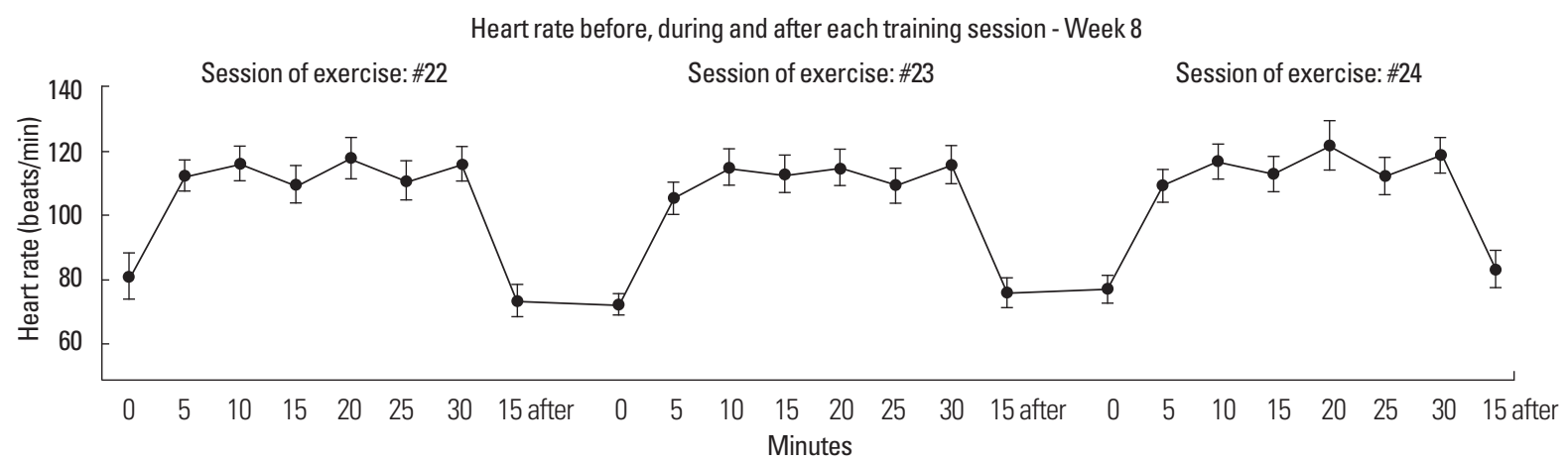

Supplementary Fig. 2. (Continued) Heart rate per minute before, during and after each of the 24 exercise sessions over 8 weeks (A-H). 